\title{
The effect of pre-pregnancy hair dye exposure on infant birth weight: a nested case-control study
}

\author{
Chao Jiang ${ }^{1,2,3,4,5+}$, Qingzhi Hou ${ }^{1,2,3,4,5 \dagger}$, Yaling Huang ${ }^{1,2,3,4}$, Juan Ye ${ }^{1,2,3,4}$, Xiaolian Qin ${ }^{6}$, Yu Zhang ${ }^{7}$, Wen Meng ${ }^{8}$, \\ Qiuyan Wang 1,2,3,4, Yonghua Jiang ${ }^{1,2,3,4}$, Haiying Zhang ${ }^{1,2,3,4,5}$, Mujun Li ${ }^{9}$, Zengnan Mo ${ }^{1,2,3,4}$ and \\ Xiaobo Yang ${ }^{1,2,3,4,5^{*}}$ (D)
}

\begin{abstract}
Background: Limited evidences were reported about the risk of pre-pregnancy hair dye use or irregular menstruation with abnormal birth weight during pregnancy, and their joint effects were also unknown. The aim of our study was to explore whether the pre-pregnancy exposure of hair dye and irregular menstruation were associated with the risk of abnormal birth weight.

Methods: We conducted a nested case-control study from a prospective cohort of 6203 pregnant women. Low birth weight study included 315 mother-infant pairs (105 LBW cases and 210 matched controls), and macrosomia study included 381 mother-infant pairs (127 macrosomia cases and 254 matched controls). Meanwhile, lifestyle information including hair dying custom and menstrual history were collected by face-to-face questionnaires and birth outcomes were extracted from the medical records. The logistic regressions models were used to analyze the join effect of irregular menstruation and hair dye use.

Results: Pre-pregnancy hair dye use was associated with increased risk of LBW (adjusted OR $=1.71,95 \%$ Cl: 1.01-2.92, $P=0.048$ ). Irregular menstruation had high risk of LBW (adjusted $\mathrm{OR}=2.79,95 \% \mathrm{Cl}: 1.53-5.09, P=0.001$ ) and macrosomia (adjusted $\mathrm{OR}=1.93,95 \% \mathrm{Cl}: 1.09-3.44, P=0.023$ ). Additionally, in the LBW study, women who used hair dye with prepregnancy $\mathrm{BMl}<18.5 \mathrm{~kg} / \mathrm{m}^{2}$ had higher OR than those with only one risk factor $\left(3.07 \mathrm{vs} 2.53, P_{\text {trend }}=0.015\right)$, and women with both hair dye use and irregular menstruation also had higher risk than those with only one factor ( 4.53 vs 2.07, $P$ trend $=0.05)$. Moreover, in macrosomia study, women with irregular menstruation and pre-pregnancy BMl $\geq 24 \mathrm{~kg} / \mathrm{m}^{2}$ had higher risk than those with one factor (13.31 vs 2.09, $P$ trend $=0.001$ ).

Conclusion: Our study showed that either pre-pregnancy hair dye use or irregular menstruation was associated with abnormal birth weight, especially, their joint effects could furthermore increase the risk of low birth weight infants when these two factors existed simultaneously.
\end{abstract}

Keywords: Hair dye use, Pre-pregnancy BMI, Irregular menstruation, Low birth weight infants, Macrosomia

\footnotetext{
* Correspondence: yangx@gxmu.edu.cn

${ }^{\dagger}$ Equal contributors

${ }^{1}$ Center for Genomic and Personalized Medicine, Guangxi Medical University,

Nanning, Guangxi Zhuang Autonomous Region, China

${ }^{2}$ Guangxi key Laboratory for Genomic and Personalized Medicine, Nanning,

Guangxi Zhuang Autonomous Region, China

Full list of author information is available at the end of the article
}

(c) The Author(s). 2018 Open Access This article is distributed under the terms of the Creative Commons Attribution 4.0 International License (http://creativecommons.org/licenses/by/4.0/), which permits unrestricted use, distribution, and reproduction in any medium, provided you give appropriate credit to the original author(s) and the source, provide a link to the Creative Commons license, and indicate if changes were made. The Creative Commons Public Domain Dedication waiver (http://creativecommons.org/publicdomain/zero/1.0/) applies to the data made available in this article, unless otherwise stated. 


\section{Background}

Abnormal birth weight is an important issue which could reflect fetal growth and maternal health, including low birth weight (LBW) infant (live infant weight < $2,500 \mathrm{~g}$ at birth) and macrosomia (live infant weight $>$ 4, $000 \mathrm{~g}$ at birth) [1]. Low birth weight infants comprise $7.6 \%$ of all live-born infants in United States $[2,3]$ and $5.87 \%$ in China [4]. Additionally, macrosomia rate is 4 to $20 \%$ in Western countries and 6.5 to $11.67 \%$ in China $[5,6]$.The abnormal birth weight might have effects on fetus or children sub-health [7-9], and even were associated with diseases such as obesity, cancer, cardiovascular diseases, hypertension and malnutrition $[5,10,11]$. Thus, newborn birth weight is regarded as a significant problem of public health [12].

The etiology of abnormal birth weight is not entirely clear now, previous studies reported maternal pre-pregnancy body mass index (BMI), life style, dietary and infection during pregnancy, et al. may have effects on abnormal birth weight $[7-9,13,14]$. As society develops, the life style of women have drastically changed, fast-paced work and irregular living habits may affect internal secretion of ovary which could affect pregnancy outcomes. Because hair dye use and irregular menstruation is increasing and becoming common during women $[15,16]$, we hypothesis certain chemicals which present in hair dye and irregular menstruation may have effect on abnormal birth weight infant. The products of hair dye contain large parts of chemical substances, such as aromatic amines, organic solvents, phthalates, formaldehyde, et al. Some studies indicated that the reproductive toxicity of chemical substances had adverse effect on birth outcomes in animal experiments [17, 18]. Previous epidemiological studies showed that occupational hair-dressers and cosmetologist had reproductive risks on abnormal pregnancy outcomes such as LBW, preterm birth, abortion, preeclampsia [19-22]. In general population, it is also common for women to have irregular menstruation, which reaches up to $30 \%$ between the age 18 and 40 [16], and those women were reported to have high risk of pregnant complications, such as low birth weight [23], preterm birth, preeclampsia, gestational diabetes mellitus,et al. [23-25]. However, few study reported the risk of hair dye use for those female customers, and simultaneously targeted the women with irregular menstruation and the hair dye use pre-pregnancy on the risk of abnormal birth weight infant.

Our present study used the nested case-control design including 4,978 pregnant women in Guangxi, China, and investigated associations between prepregnancy hair dye use, irregular menstruation and the risk of abnormal birth weight.

\section{Methods}

\section{Study design and population}

The nested case-control study is based on an ongoing collaborate prospective of Guangxi Birth Cohort Study (GBCS), which contains seven Maternal \& Child Health Hospitals and aims to investigate the effects of genetic and environmental factors on pregnancy outcomes. The inclusion criteria of GBCS required the volunteers to be $18-45$ years old, born in and live in the study areas and have comprehensive ability to complete a face-to-face interview questionnaire. A total of 6, 203 pregnant women were recruited during prenatal examination at those hospitals from July to September in 2015. In the end, 5, 541 pregnancies were followed-up after they completed the delivery.

In the nested case-control study, the exclusion criteria were: (1) Preterm delivery $(<37$ gestational weeks), multiple birth, unknown infant gender, abortion, stillbirth and birth defect. (2) Women who used birth control pills or contraceptive injection less than few months prior to pregnancy or did any fertility treatment were excluded. After exclusions, 4, 978 single live full-term infant-mother pairs were selected for the final study, contained $105 \mathrm{LBW}$ infants and 127 macrosomia. The selection of the controls was as follows: (1) Mothers delivered a singleton live full-term infant with normal birth weight. (2) For each case, two controls were randomly selected from the normal birth-weight subjects based on the matching variables as fetal gender, approximate gestational age at conception (within 1 -week interval), maternal age (within 1-age interval) and recruitment area According to the matching constraints, separately 210 normal birth-weight births were matched for low birth weight cases and 254 controls were matched for macrosomia cases.

\section{Data collection}

The detailed questionnaire collected information, regarding demographic factors (education level, maternal age and pre-pregnancy height and weight by selfreported, et al...), personal lifestyle (smoking, alcohol consumption and hair dye use history, et al), pregnancy history (gravidity and parity), pregnancy complications, medication history (pre-pregnancy use and during pregnancy use), physical activity, dietary, psychological factors and the menstrual history. Pregnant women were followed-up until delivery, and the information of pregnant women (age, parity, pregnant disease, and gravidity) and infants (gender, Apgar score of $5 \mathrm{~min}$, weight, length, head and chest circumference) were obtained from the Guangxi Maternal and Child Health Information System.

Hair dye exposure was defined as women used hair dye before conception which was collected from 
questionnaires by self-reported. Irregular menstruation was defined as menstrual cycle persistently outside 2145 days [20] by self-reported [13]. The neonatal outcome of this study was live infant birth weight which was calculated within 5 min after birth. $<2$, $500 \mathrm{~g}$ is low birth weight, and macrosomia is $>4,000 \mathrm{~g}$ at birth [1]. Gestational age was assessed by means of the date of the last menstrual period and fetal biometry in the first trimester ultrasound scan.

\section{Ethical approval}

Study protocol data collection was approved by Medical Ethics Committee of First Affiliated Hospital of Guangxi Medical University (ID: 2015(028)). All patients consented to participate in the research, and written informed consent was obtained from each patient.

\section{Statistical analysis}

Significant differences were assessed by t-test for continuous variables (means with $1 \mathrm{SD}$ ) or chi-square tests for categorical variables (frequency and percentage). Binary logistic regression analyses were used examine the risk of dichotomized exposures associated with abnormal birth weight. Crude and adjusted Odds ratios (ORs) were calculated and 95\% confidence intervals (CIs) were given. The pre-pregnancy hair dye use and maternal irregular menstruation were analyzed as categorical variables. A $P$ value $<0.05$ in 2 -tailed tests was considered statistically significant. Statistical analysis was performed using SPSS version 21.0 (IBM).

\section{Results}

\section{General characteristic}

The nested case-control study contained two substudies, which were low birth weight (LBW) study and macrosomia study, respectively. General characteristic of maternal and neonatal are presented in Tables 1 and 2 .

In the low birth weight study, compared to controls, there were lower pre-pregnant height and weight, and a higher proportion of irregular menstruation $(29.5 \%$ vs $12.9 \%$ ), all $P<0.05$ (Table 1). Meanwhile, the hair dye use of case mothers had higher proportion than controls (71.4\% vs $60 \%$ ) (Table 2 ).

In the macrosomia study, compared to controls, the pregnant women had higher maternal age, pre-pregnant height, and weight, and a higher proportion of first parity (55.9\% vs $42.9 \%)$, menstrual irregularity ( $27.6 \%$ vs 16 . $2 \%)$ and low education level ( $\leq 9$ years) $(53.5 \%$ vs $33.5 \%)$ (Table 1). However, no statistical significance was observed among other characteristics of selected lifestyle in this study (Table 2).

Comparison of each sub-study group, there were no significant differences of maternal menarche age, gravidity history, alcohol use before pregnancy, smoking status, progesterone use before and during pregnancy, nearby chemical factory, recent interior decoration, regularly cooking, chief fuel used for cooking, use of range hood, radiation-proof clothes and lipstick use during pregnancy (All $P>0.05$ ) (Tables 1 and 2).

\section{Relationship of maternal irregular menstruation and abnormal birth weight}

Table 3 showed the estimated associations between considered exposures variables and the risk of abnormal birth weight. Women with irregular menstruation had significantly higher odds of having $L B W$ infants $(O R=2$. 84, 95\%CI: $1.59-5.08, P<0.001)$ and macrosomia $(\mathrm{OR}=$ 1.97, 95\% CI: $1.18-3.29, P<0.001)$, respectively compared to the pregnant women with regular menstruation. After adjusted by maternal age, education level and prepregnant BMI, the associations were still statistically significant (LBW: adjusted OR $=2.79,95 \%$ CI: $1.53-5.09$, $P=0.001$. Macrosomia: adjusted $\mathrm{OR}=1.93,95 \% \mathrm{CI}: 1$. 09-3.44, $P=0.023)$.

\section{Relationship of hair dye use and abnormal birth weight}

An increased risk of hair dye use associated with low birth weight was observed in LBW study $(\mathrm{OR}=1.67$, 95\% CI: $1.01-2.76$, adjusted OR $=1.71,95 \%$ CI: $1.01-2$. 92, all $P<0.05)$. However, there were no statistical significance in macrosomia study $(\mathrm{OR}=0.74,95 \% \mathrm{CI}$ : 0 . 48-1.15, adjusted OR $=0.75,95 \%$ CI: $0.46-1.23$, all $P>0$. 05).The confounding factors including maternal age, maternal education level and pre-pregnant body mass index were adjusted in the logistic regression analysis (Table 3).

\section{Joint effects on low birth weight study}

When we combined irregular menstruation and hair dye use, the odds of having a LBW baby was higher than those only had one risk(OR: 4.58 vs $2.16, P<0.05)$. Meanwhile, when combined with $\mathrm{BMI}<18.5 \mathrm{~kg} / \mathrm{m}^{2}$ and hair dye use, the odds of having a LBW infant had a little higher (OR: 2.96 vs $2.52, P<0.05$ ) (Table 4). Interestingly, even adjusted by confounders, the associations were still striking in each sub-study (Table 4).

\section{Joint effects on macrosomia study}

When we combined women with pre-pregnancy $\mathrm{BMI} \geq$ $24 \mathrm{~kg} / \mathrm{m}^{2}$ and irregular menstruation, the risk of having a macrosomia was much higher than those had only one factor (OR: 13.05 vs 2.12 , all $P<0.05$ ). After adjusted by maternal age, maternal education level, parity and prepregnancy hair dye use, the risk was still striking $\left(\mathrm{OR}_{\text {adjusted: }}\right.$ 13.31 vs 2.09 ) (Table 5 ). 
Table 1 Baseline characteristics of two sub-study subjects

\begin{tabular}{|c|c|c|c|c|c|c|}
\hline \multirow[t]{2}{*}{ Characteristics } & \multicolumn{3}{|c|}{ LBW group $(n=315)$} & \multicolumn{3}{|c|}{ Macrosomia group $(n=381)$} \\
\hline & LBW (\%) & NBW (\%) & $p^{a}$ & $\overline{\text { Macrosomia (\%) }}$ & NBW (\%) & $p^{a}$ \\
\hline $\bar{N}$ & 105 & 210 & & 127 & 254 & \\
\hline Maternal age (years) [mean (SD)] & $28(4.7)$ & $28.2(4.9)$ & 0.753 & $29.9(5.2)$ & $27.7(4.8)$ & $<0.001$ \\
\hline Pre-pregnant height (cm) [mean (SD)] & $156.1(4.3)$ & $157.7(4.7)$ & 0.003 & $56.8(8.6)$ & $50(7.6)$ & $<0.001$ \\
\hline Pre-pregnant weight (kg) [mean (SD)] & $47.8(7.5)$ & $51(8.3)$ & 0.001 & $158.4(4.6)$ & $157.3(4.8)$ & 0.047 \\
\hline Pre-pregnant BMl categories $\left(\mathrm{kg} / \mathrm{m}^{2}\right)$ & & & 0.073 & & & $<0.001$ \\
\hline$<18.5$ & $40(38.5)$ & $56(26.7)$ & & $8(6.5)$ & $78(30.7)$ & \\
\hline $18.5-23.9$ & $55(52.9)$ & $125(59.5)$ & & $79(63.7)$ & $153(60.2)$ & \\
\hline$\geq 24$ & $9(8.7)$ & $29(13.8)$ & & $37(29.8)$ & $23(9.1)$ & \\
\hline Age at menarche (years) [mean (SD)] & $13.4(1.5)$ & $13.5(1.5)$ & 0.846 & $13.3(2.1)$ & $13.6(1.7)$ & 0.184 \\
\hline Gravidity history & & & 0.212 & & & 0.073 \\
\hline First & $44(41.9)$ & $67(31.9)$ & & $28(22.0)$ & $71(28.0)$ & \\
\hline $2-3$ & $46(43.8)$ & $106(50.5)$ & & $69(54.3)$ & $146(57.5)$ & \\
\hline$>3$ & $15(14.3)$ & $37(17.6)$ & & $30(23.6)$ & $37(14.6)$ & \\
\hline Parity history & & & 0.145 & & & 0.017 \\
\hline First & $37(35.2)$ & $92(43.8)$ & & $71(55.9)$ & $109(42.9)$ & \\
\hline$\geq 2$ & $68(64.8)$ & $118(56.2)$ & & $56(44.1)$ & $145(57.1)$ & \\
\hline Menstrual regularity & & & $<0.001$ & & & 0.009 \\
\hline Yes & $74(70.5)$ & $183(87.1)$ & & $92(72.4)$ & $212(83.8)$ & \\
\hline Education level (years) & & & 0.909 & & & $<0.001$ \\
\hline$\leq 9$ & $38(36.2)$ & $72(34.3)$ & & $68(53.5)$ & $85(33.5)$ & \\
\hline $10-12$ & $32(30.5)$ & $63(30.0)$ & & $30(23.6)$ & $72(28.4)$ & \\
\hline$\geq 13$ & $35(33.3)$ & $75(35.7)$ & & $29(22.8)$ & 97 (39.2) & \\
\hline Alcohol use pre-pregnancy & & & 0.854 & & & 0.094 \\
\hline Yes & $27(25.7)$ & $52(24.8)$ & & $70(27.6)$ & $25(19.7)$ & \\
\hline Smoking status & & & 0.213 & & & 0.554 \\
\hline Current / ex-smoker & $3(2.9)$ & $1(0.5)$ & & $2(0.8)$ & $0(0)$ & \\
\hline Second-hand smoking & & & 0.657 & & & 0.257 \\
\hline Yes & $16(15.2)$ & $28(13.4)$ & & $26(10.2)$ & $18(14.2)$ & \\
\hline Progesterone use pre-pregnancy & & & 0.282 & & & 0.857 \\
\hline Yes & $1(1.0)$ & $8(3.8)$ & & $11(4.3)$ & $5(3.9)$ & \\
\hline Progesterone use during pregnancy & & & 0.375 & & & 1.000 \\
\hline Yes & $26(24.8)$ & $62(29.5)$ & & $38(29.9)$ & $76(29.9)$ & \\
\hline
\end{tabular}

Abbreviations: $L B W$ low birth weight, NBW new birth weight, $S D$ standard deviation, \% percentages estimated on valid data only, $B M I$ body mass index is measured and defined as weight $(\mathrm{kg}) /$ height $(\mathrm{m})^{2}$

${ }^{a}$ T-tests and Chi-square tests were used to test differences in two sub-study subjects

\section{Discussion}

To our knowledge, this is the first nested case-control study to report the association of combined prepregnancy hair dye use and irregular menstruation with abnormal birth weight in China. In this study, we found that women who used hair dye pre-pregnancy had significantly high risk of low birth weight infants. Simultaneously, women with irregular menstruation had significantly high risk of low birth weight infants and macrosomia. Then, when we combined the hair dye use pre-pregnancy and irregular menstruation, we found the risk of low birth weight infants were higher than those with only one risk factor. Our results showed that women with exposure of hair dye pre-pregnancy and irregular menstruation had an increased risk of low birth weight infant.

As society develops, hair dye using is rapid increasing and becoming common during women. Recent studies focused on the effects of occupational exposure to chemical substances which persist in hair care products 
Table 2 Selected lifestyle characteristics of two sub-study subjects

\begin{tabular}{|c|c|c|c|c|c|c|}
\hline \multirow[t]{2}{*}{ Exposure variables } & \multicolumn{3}{|c|}{ LBW group $(n=315)$} & \multicolumn{3}{|c|}{ Macrosomia group $(n=381)$} \\
\hline & LBW (\%) & NBW (\%) & $p^{a}$ & Macrosomia (\%) & NBW (\%) & $p^{a}$ \\
\hline $\mathrm{N}$ & 105 & 210 & & 127 & 254 & \\
\hline Nearby chemical factory & & & 0.303 & & & 0.934 \\
\hline Yes & $4(3.8)$ & $14(6.7)$ & & $4(3.2)$ & $10(3.9)$ & \\
\hline Recent interior decoration & & & 0.279 & & & 0.374 \\
\hline Yes & $13(12.5)$ & $36(17.2)$ & & $18(14.2)$ & $28(11.0)$ & \\
\hline Regularly cooking & & & 0.806 & & & 0.094 \\
\hline Yes & $76(72.4)$ & $154(73.3)$ & & $97(76.4)$ & $173(68.1)$ & \\
\hline Chief fuel used for cooking & & & 0.989 & & & 0.920 \\
\hline Pollution-type & $11(10.6)$ & $22(10.5)$ & & $15(11.8)$ & $29(11.5)$ & \\
\hline Ecological and clean-type & $93(89.4)$ & $187(89.5)$ & & $112(88.2)$ & $224(88.5)$ & \\
\hline Use of range hood & & & 0.285 & & & 0.876 \\
\hline Yes & $72(68.6)$ & $156(74.3)$ & & $88(69.3)$ & $174(68.5)$ & \\
\hline Pets & & & 0.584 & & & 0.731 \\
\hline Yes & $29(27.6)$ & $52(24.8)$ & & $28(22.0)$ & $60(23.6)$ & \\
\hline Radiation-proof clothes use during pregnancy & & & 0.978 & & & 1.000 \\
\hline Yes & $11(10.6)$ & $22(10.5)$ & & 15(11.8) & $30(11.8)$ & \\
\hline Lipstick use during pregnancy & & & 0.717 & & & 0.054 \\
\hline Yes & $6(5.7)$ & $10(4.8)$ & & $2(1.6)$ & $15(5.9)$ & \\
\hline Hair dye use pre-pregnancy & & & 0.047 & & & 0.175 \\
\hline Yes & $75(71.4)$ & $126(60.0)$ & & $75(59.1)$ & $168(66.1)$ & \\
\hline
\end{tabular}

Abbreviations: $L B W$ low birth weight, NBW new birth weight

${ }^{\mathrm{a}} \mathrm{T}$-tests and Chi-square tests were used to test differences in two sub-study subjects

on abnormal birth outcome and maternal complications in hairdressers [20-22, 26-29] and compared with salesclerks[21, 30-32], but the results are inconsistent. A meta-analysis showed hairdressers and cosmetologists had a significant increased risk of neonatal complications, such as LBW, fetal loss, SGA (small for gestational age) $[33,34]$. Our results showed women customers who used hair dye pre-pregnancy had high risk of LBW (OR adjusted $=1.71,95 \%$ CI: $1.01-2.92$ ).

The use of hair dye is popular between women however different components of chemical substance can be found on it. A Canadian study found the hair dye production contained at least one phthalate at a detectable level [35]. Based on the results of the epidemiological studies examined, we therefore hypothesized that the products of hair dye contains chemical substances such as ultraviolet filters, phthalate esters and parabens, et al., which suspected to endocrine disrupters [36, 37]. Endocrine disorder of women may influence the secretion of progestational hormone which could increase the risk of LBW. Also, different hair dye with less chemical products could have lower influence on LBW.

Table 3 Logistic regression analysis of hair dye use pre-pregnancy, irregular menstruation, parity and birth weight

\begin{tabular}{|c|c|c|c|c|c|c|c|c|}
\hline & \multicolumn{4}{|l|}{ LBW } & \multicolumn{4}{|l|}{ Macrosomia } \\
\hline & \multirow{2}{*}{$\begin{array}{l}\text { Unadjusted } \\
\text { OR (95\% Cl) }\end{array}$} & \multirow[t]{2}{*}{$P$} & Adjusted $^{a}$ & \multirow[t]{2}{*}{$P$} & \multirow{2}{*}{$\begin{array}{l}\text { Unadjusted } \\
\text { OR (95\% Cl) }\end{array}$} & \multirow[t]{2}{*}{$P$} & \multirow{2}{*}{$\begin{array}{l}\text { Adjusted b } \\
\text { OR (95\% Cl) }\end{array}$} & \multirow[t]{2}{*}{$P$} \\
\hline & & & OR $(95 \% \mathrm{Cl})$ & & & & & \\
\hline Hair dye use pre-pregnancy & $1.67(1.01,2.76)$ & 0.048 & $1.71(1.01,2.92)$ & 0.048 & $0.74(0.48,1.15)$ & 0.180 & $0.75(0.46,1.23)$ & 0.259 \\
\hline Irregular menstruation & $2.84(1.59,5.08)$ & $<0.001$ & $2.79(1.53,5.09)$ & 0.001 & $1.97(1.18,3.29)$ & $<0.001$ & $1.93(1.09,3.44)$ & 0.023 \\
\hline \multicolumn{9}{|l|}{ Parity history } \\
\hline First & $1.43(0.88,2.33)$ & 0.150 & $1.45(0.83,2.53)$ & 0.189 & $0.59(0.39,0.91)$ & 0.017 & $1.14(0.67,1.94)$ & 0.643 \\
\hline$\geq 2$ & 1.00 (Reference) & & 1.00 (Reference) & & 1.00 (Reference) & & 1.00 (Reference) & \\
\hline
\end{tabular}

Abbreviations: $L B W$ low birth weight, $95 \%$ Cl confidence interval, OR odds ratio

a, b Logistic regression models are adjusted for potential confounders (maternal age, maternal education level and pre-pregnant body mass index) as described in methods 
Table 4 Combined effects of underweight / irregular menstruation and hair dye use pre-pregnancy on LBW study

\begin{tabular}{|c|c|c|c|c|c|c|}
\hline & \multicolumn{3}{|l|}{ Unadjusted } & \multicolumn{3}{|l|}{ Adjusted } \\
\hline & $\mathrm{OR}(95 \% \mathrm{Cl})$ & $P$ & $P_{\text {trend }}$ & $\mathrm{OR}(95 \% \mathrm{Cl})$ & $P$ & $P_{\text {trend }}$ \\
\hline \multicolumn{7}{|l|}{ Type-1 model ${ }^{a}$} \\
\hline Neither of them & 1.00 (Reference) & & & 1.00 (Reference) & & \\
\hline Only $\mathrm{BMI}<18.5 \mathrm{~kg} / \mathrm{m}^{2}$ or hair dye use pre-pregnancy & $2.52(1.33,4.78)$ & 0.005 & 0.012 & $2.53(1.30,4.93)$ & 0.006 & 0.015 \\
\hline Both $\mathrm{BMI}<18.5 \mathrm{~kg} / \mathrm{m}^{2}$ and hair dye use pre-pregnancy & $2.96(1.39,6.33)$ & 0.005 & & $3.07(1.38,6.83)$ & 0.006 & \\
\hline \multicolumn{7}{|l|}{ Type-2 model ${ }^{b}$} \\
\hline Neither of them & 1.00 (Reference) & & & 1.00 (Reference) & & \\
\hline Only irregular menstruation or hair dye use pre-pregnancy & $2.16(1.20,3.89)$ & 0.010 & 0.030 & $2.07(1.14,3.76)$ & 0.018 & 0.050 \\
\hline Both irregular menstruation and hair dye use pre-pregnancy & $4.58(2.02,10.40)$ & $<0.001$ & & $4.53(1.94,10.59)$ & $<0.001$ & \\
\hline
\end{tabular}

Abbreviations: $L B W$ low birth weight, OR odds ratio, 95\% Cl 95\% confidence interval, BMI body mass index is measured and defined as weight (kg) / height (m) ${ }^{2}$ aLogistic regression model is adjusted for maternal age, maternal education level, parity and menstruation cycle

${ }^{\mathrm{b}}$ Logistic regression model is adjusted for maternal age, maternal education level, parity and pre-pregnant body mass index

Irregular menstruation may be the other risk factor for abnormal birth weight infant. Our study reported that women with irregular menstruation had significant association of LBW $(\mathrm{OR}=2.84,95 \% \mathrm{CI}: 1.59-5.08)$ and macrosomia (OR $=1.97,95 \% \mathrm{CI}: 1.18-3.29)$. The results were consistence with previous studies [23, 38-41], but conflict with the study of Wang ET [42], which reported that obese women with irregular menstruation had significantly risk of lower birth weight compared with regular subjects. Inconsistent results may be due to different menstrual cycle, different sample size, study population and different study design etc. Besides of the conflictive results, our results were in line with most of previous studies.

Irregular menstruation may indicate ovulation disturbances which associated with sub-fertility. Women with sub-fertility were spontaneously considered to have a risk of abnormal birth outcomes, such as preeclampsia, low birth weight, preterm birth, abortion and stillbirth [43]. Dysfunction of the endocrine system could affect concentration of serum insulin-like growth factor1(ILGH-1), which associated with infant birth weight [44-47]. Besides, the concentrations dynamically changed during different stages, which increased in the early pubertal stages and then slowly decreased in late stages [48]. In addition, Xu et al. [49] speculated that the physiology effect of ILGH-1 on fetal growth could be a possible link between abnormal birth weight and maternal irregular menstruation.
Interestingly, when we combined hair dye use with irregular menstruation, the risk of LBW was significantly higher than those had only one risk (OR: 4.58 vs 2.16 ), which indicated that two factors simultaneously existed would highly strengthen the risk of LBW. As we knew, this is the first report about the joint effect of hair dye use and irregular menstruation on low birth weight infant. A Japanese study showed that the frequently use of hair dye was associated with an increased risk of abnormal circulating testosterone levels [50], which could affect the concentration of serum insulin-like growth factor - 1(ILGH-1) [44-47]. And then, Xu et al. recognized irregular menstruation also affect the secretion of ILGH-1 [49]. When these two risk factors simultaneously existed, the concentration of ILGH-1 would have greatly change, and the effect on the abnormal birth weight would be much stronger. This is a significant discovery for antenatal and newborn care.

Pre-pregnancy BMI may be other risk factors of abnormal birth weight infants. Previous studies showed that women either underweight or overweight and obese had unhealthy impacts on birth weight [51-54].Our study showed that women who used hair dye with $\mathrm{BMI}<18$. $5 \mathrm{~kg} / \mathrm{m}^{2}$ had higher risk of low birth weight infants than those had one factor (OR: 3.07 vs $2.53, P$ trend $=0.015$ ), irregular menstruation women with $B M I \geq 24 \mathrm{~kg} / \mathrm{m}^{2}$ had higher risk of macrosomia than one factor existed (OR: 13.31 vs $2.09, P$ trend $=0.001$ ). This indicated that women with abnormal pre-pregnancy BMI with irregular

Table 5 Combined effect of overweight and irregular menstruation on macrosomia study

\begin{tabular}{|c|c|c|c|c|c|c|}
\hline & \multicolumn{3}{|l|}{ Unadjusted } & \multicolumn{3}{|l|}{ Adjusted $^{a}$} \\
\hline & $\mathrm{OR}(95 \% \mathrm{Cl})$ & $P$-Value & $P_{\text {trend }}$ & OR $(95 \% \mathrm{Cl})$ & $P$-Value & $P_{\text {trend }}$ \\
\hline Neither of them & 1.00 (Reference) & & & 1.00 (Reference) & & \\
\hline Only $\mathrm{BMI} \geq 24 \mathrm{~kg} / \mathrm{m}^{2}$ or irregular menstruation & $2.12(1.32,3.43)$ & 0.002 & 0.001 & $2.09(1.26,3.45)$ & 0.004 & 0.001 \\
\hline Both $\mathrm{BMI} \geq 24 \mathrm{~kg} / \mathrm{m}^{2}$ and irregular menstruation & $13.05(3.64,46.80)$ & $<0.001$ & & $13.31(3.54,50.11)$ & $<0.001$ & \\
\hline
\end{tabular}

Abbreviations: OR odds ratio, 95\% Cl 95\% confidence interval, BMI body mass index is measured and defined as weight (kg) / height (m) ${ }^{2}$

a Logistic regression model is adjusted for maternal age, maternal education level, parity and hair dye use 
menstruation or hair dye use could further strengthen the risk of abnormal birth weight infants.

The advantage of this study was the prospective design in a large sample aimed to investigate the relationship of hair dye use or irregular menstruation with infant birth weight. In addition, there were several limitations in our study. First, the information of irregular menstruation was collected by women self-reported, retrospective bias was inevitable. In future study, we could consider combine ultrasound examination-based gestational age and self-reported. Second, the detailed information of pre-pregnancy hair dye use, including the frequency and name or types of products, were not collected, which limited the quantity study of hair dye use with abnormal birth weight. This will be considered in future studies. Third, our nested case-control study did not have a large number of subjects even though the birth cohort study sample was a good number. In addition, we will do further studies because the evidences of reporting the risk of pre-pregnancy hair dye use or irregular menstruation with abnormal birth weight are limited at present.

\section{Conclusions}

From this nested case-control study, we found that either pre-pregnancy hair dye use or irregular menstruation was associated with abnormal birth weight in China, indicating that pre-pregnancy exposure to hair dye and irregular menstruation may be risk factors for abnormal birth weight infants.

\section{Abbreviations}

BMI: Body mass index; Cl: Confidence interval; ILGH-1: Insulin-like growth factor-1; LBW: Low birth weight; NBW: New birth weight; OR: Odds ratio; SD: Standard deviation

\section{Acknowledgements}

We are extremely grateful to all the participants in our study and sincerely thank the department of Maternal and Child Health Services of The Guangxi Zhuang Autonomous Region Health and Family Planning Commission.

\section{Funding}

This study was funded by the Fok Ying-Tong Education Foundation (141118), the National Natural Science Foundation of China (81370857), Guangxi science and technology project (GKG1598011-3), and the Guangxi Natural Science Foundation (2013GXNSFFA019002).

\section{Availability of data and materials}

The datasets used and/or analysed during the current study are available from the corresponding author on reasonable request.

\section{Authors' contributions}

$X Y, C J, Q H$ contributed to the design of the study, QH and CJ drafted the initial manuscript. CJ completed the statistical analysis under the help of XY, YH and JY. CJ, YH and JY collected data and completed the data input under the supervision of $X Y . X Q, Y Z$ and $W M$ provided scientific advice on the process of data acquisition and made data interpretation. QW, YJ, HZ, $M L, Z M$ and $X Y$ completed the design of cohort study. $X Y, C J, Q H$ contributed in reviewing the final manuscript. All authors contributed to drafting the paper and have read and approved the final manuscript.
Ethics approval and consent to participate

Medical Ethics Committee of First Affiliated Hospital of Guangxi Medical University approved the study protocol data collection, and written informed consent was obtained from each patient.

\section{Competing interests}

The authors declare that they have no competing interests.

\section{Publisher's Note}

Springer Nature remains neutral with regard to jurisdictional claims in published maps and institutional affiliations.

\section{Author details}

${ }^{1}$ Center for Genomic and Personalized Medicine, Guangxi Medical University, Nanning, Guangxi Zhuang Autonomous Region, China. ${ }^{2}$ Guangxi key Laboratory for Genomic and Personalized Medicine, Nanning, Guangxi Zhuang Autonomous Region, China. ${ }^{3}$ Guangxi Collaborative Innovation Center for Genomic and Personalized Medicine, Nanning, Guangxi Zhuang Autonomous Region, China. ${ }^{4}$ Guangxi Key Laboratory of Colleges and Universities, Nanning, Guangxi Zhuang Autonomous Region, China. ${ }^{5}$ Department of Occupational and Environmental Medicine School of Public Health, Guangxi Medical University, 22 Shuangyong Rd, Nanning 530021, Guangxi, China. ${ }^{6}$ Department of Antenatal care, the Maternal \& Child Health Hospital of Yulin, Yulin, Guangxi, China. ${ }^{7}$ Department of Gynecology and Obstetrics, the Maternal \& Child Health Hospital of Liuzhou, Liuzhou, Guangxi, China. ${ }^{8}$ Department of Medical Services Section, the Maternal \& Child Health Hospital of Guigang, Guigang, Guangxi, China. ${ }^{9}$ Department of Reproductive Center, First Affiliated Hospital of Guangxi Medical University, Nanning, Guangxi, China.

Received: 9 January 2018 Accepted: 26 April 2018

Published online: 09 May 2018

\section{References}

1. Harder T, Roepke K, Diller N, Stechling Y, Dudenhausen JW, Plagemann A. Birth weight, early weight gain, and subsequent risk of type 1 diabetes: systematic review and meta-analysis. Am J Epidemiol. 2009;169(12):1428-36.

2. Wang X, Zuckerman B, Pearson C, Chen GKC, Wang G, Niu T, Wise PH, Baychner $\mathrm{H}$, Xu X. Maternal cigarette smoking metabolic gene polymorphism, and infant birth weight. J Am Med Assoc. 2002;287(2):195-202.

3. McGaw T. Periodontal disease and preterm delivery of low-birth-weight infants. Journal. 2002;68(3):165-9.

4. Chen Y, Li G, Ruan Y, Zou L, Wang X, Zhang W. An epidemiological survey on low birth weight infants in China and analysis of outcomes of full-term low birth weight infants. BMC Pregnancy Childbirth. 2013;26(13):242.

5. Henriksen T. The macrosomic fetus: a challenge in current obstetrics. Acta Obstet Gynecol Scand. 2008;87(2):134-45.

6. Yu D, Zhai F, Zhao L, Liu A, Yu W, Jia F, Zhang J, Li J. The incidence of macrosomia and influencing factors in China in 2006. Chinese J Child Health Care. 2008;16(1):11-3.

7. Ding G, Cui C, Chen L, Gao Y, Zhou Y, Shi R, Tian Y. Prenatal exposure to pyrethroid insecticides and birth outcomes in rural northern China. J Expo Sci Environ Epidemiol. 2015:25(3):264-70.

8. Park JH, Lee BE, Park HS, Ha EH, Lee SW, Kim YJ. Association between prepregnancy body mass index and socioeconomic status and impact on pregnancy outcomes in Korea. J Obstet Gynaecol Res. 2011;37(2):138-45.

9. Rhee J, Kim R, Kim Y, Tam M, Lai Y, Keum N, Oldenburg CE. Maternal caffeine consumption during pregnancy and risk of low birth weight: a dose-response meta-analysis of observational studies. PLoS One. 2015; 10(7):e0132334

10. Cheng YK, Lao TT, Sahota DS, Leung VK, Leung TY. Use of birth weight threshold for macrosomia to identify fetuses at risk of shoulder dystocia among Chinese populations. Int J Gynaecol Obstet. 2013;120(3):249-53.

11. Gu S, An X, Fang L, Zhang X, Zhang C, Wang J, Liu Q, Zhang Y, Wei Y, Hu Z, et al. Risk factors and long-term health consequences of macrosomia: a prospective study in Jiangsu Province, China. J Biomed Res. 2012;26(4):235-40.

12. Valero De Bernabe J, Soriano T, Albaladejo R, Juarranz M, Calle ME, Martinez D, Dominguez-Rojas $\vee$. Risk factors for low birth weight: a review. Eur J Obstet Gynecol Reprod Biol. 2004;116(1):3-15. 
13. Kind KL, Moore VM, Davies MJ. Diet around conception and during pregnancy-effects on fetal and neonatal outcomes. Reprod BioMed Online. 2006;12(5):532-41.

14. Liu L, Wang J, Shao S, Luo X, Kong R, Zhang X, Song R. Descriptive epidemiology of prenatal and perinatal risk factors in a Chinese population with reading disorder. Sci Rep. 2016;6:36697.

15. Couto AC, Ferreira JD, Rosa AC, Pombo-de-Oliveira MS, Koifman S, Brazilian Collaborative Study Group of Infant Acute L. Pregnancy, maternal exposure to hair dyes and hair straightening cosmetics, and early age leukemia. Chem Biol Interact. 2013;205(1):46-52

16. Munster K, Schmidt L, Helm P. Length and variation in the menstrual cycle-a cross-sectional study from a Danish county. Br J Obstet Gynaecol. 1992;99(5):422-9.

17. Lottrup G, Andersson AM, Leffers H, Mortensen GK, Toppari J, Skakkebaek $\mathrm{NE}$, Main KM. Possible impact of phthalates on infant reproductive health. Int J Androl. 2006;29(1):172-80. discussion 181-175

18. van Muiswinkel WJ, Kromhout H, Onos T, Kersemaekers W. Monitoring and modelling of exposure to ethanol in hairdressing salons. Ann Occup Hyg. 1997:41(2):235-47.

19. Peters C, Harling M, Dulon M, Schablon A, Torres Costa J, Nienhaus A. Fertility disorders and pregnancy complications in hairdressers - a systematic review. J Occup Med Toxicol. 2010;5:24.

20. Herdt-Losavio ML, Lin S, Druschel CM, Hwang S-A, Mauer MP, Carlson GA. The risk of having a low birth weight or preterm infant among cosmetologists in New York state. Matern Child Health J. 2009;13(1):90-7.

21. Ronda E, Moen BE, García AM, Sánchez-Paya J, Baste V. Pregnancy outcomes in female hairdressers. Int Arch Occup Environ Health. 2010;83(8):945-51.

22. Rylander L, Källén B. Reproductive outcomes among hairdressers. Scand J Work Environ Health. 2005;31(3):212-7.

23. Bonnesen B, Oddgeirsdottir HL, Naver KV, Jorgensen FS, Nilas L. Women with minor menstrual irregularities have increased risk of preeclampsia and low birthweight in spontaneous pregnancies. Acta Obstet Gynecol Scand. 2016;95(1):88-92.

24. Fruscalzo A, Bertozzi S, Londero AP, Biasioli A, Driul L, Kiesel L, Marchesoni D. Menstrual abnormalities and predisposition to pregnancy-related hypertensive disorders: a retrospective study. Gynecol Endocrinol. 2010;26(6):445-50.

25. Haver MC, Locksmith GJ, Emmet E. Irregular menses: an independent risk factor for gestational diabetes mellitus. Am J Obstet Gynecol. 2003; 188(5):1189-91.

26. Meyer JD, Nichols GH, Warren N, Reisine S. Maternal occupation and risk for low birth weight delivery: assessment using state birth registry data. J Occup Environ Med. 2008;50(3):306-15.

27. Onaran Y, Aktepe KeskiN E, ZC ILIRD, SA SiM, Koca C, Kafali H, Turhan N Prohepcidin in maternal circulation: is it related to spontaneous preterm labor? Turk J Med Sci. 2014;44:1108-13.

28. Halliday-Bell JA, Gissler M, Jaakkola JJ. Work as a hairdresser and cosmetologist and adverse pregnancy outcomes. Occup Med. 2009;59(3):180-4.

29. Turitz AL, Ackerman CM, Johnson DL, Bank TC, Duong JK, Lee SM, GyamfiBannerman C. A comparison of prevaginal and postvaginal manipulation fetal fibronectin. Am J Obstet Gynecol. 2016;214(5):646. e641-646

30. Kersemaekers WM, Roeleveld N, Zielhuis GA. Reproductive disorders among hairdressers. Epidemiology (Cambridge, Mass). 1997;8(4):396-401.

31. Baste V, Moen BE, Riise T, Hollund BE, Øyen N. Infertility and spontaneous abortion among female hairdressers: the Hordaland health study. J Occup Environ Med. 2008:50(12):1371-7.

32. Ronda E, Garcia AM, Sanchez-Paya J, Moen BE. Menstrual disorders and subfertility in Spanish hairdressers. Eur J Obstet Gynecol Reprod Biol. 2009;147(1):61-4.

33. von Schoning D, Fischer T, von Tucher E, Slowinski T, Weichert A, Henrich W, Thomas A. Cervical sonoelastography for improving prediction of preterm birth compared with cervical length measurement and fetal fibronectin test. J Perinat Med. 2015:43(5):531-6.

34. Henrotin J-B, Picot C, Bouslama M, Collot-Fertey D, Radauceanu A, Labro MT, Larroque B, Roudot A-C, Sater N, Elhkim MO, et al. Reproductive disorders in hairdressers and cosmetologists: a meta-analytical approach. J Occup Health. 2015:57(6):485-96.

35. Koniecki D, Wang R, Moody RP, Zhu J. Phthalates in cosmetic and personal care products: concentrations and possible dermal exposure. Environ Res. 2011;111(3):329-36.

36. Witorsch RJ, Thomas JA. Personal care products and endocrine disruption: a critical review of the literature. Crit Rev Toxicol. 2010;40(Suppl 3):1-30.
37. Dodson RE, Nishioka M, Standley LJ, Perovich LJ, Brody JG, Rudel RA. Endocrine disruptors and asthma-associated chemicals in consumer products. Environ Health Perspect. 2012;120(7):935-43.

38. Nguyen $\mathrm{TH}$, Larsen $\mathrm{T}$, Engholm $\mathrm{G}$, Møller $\mathrm{H}$. Increased adverse pregnancy outcomes with unreliable last menstruation. Obstet Gynecol. 2000;95(6 Pt 1):867-73.

39. Hakala T. Obstetric care, pregnancy risk factors and perinatal outcome in the province of Uusimaa, Finland, in 1980-1981. Ann Chir Gynaecol Suppl. 1987:203:1-83.

40. Hizli D, Kosus A, Kosus N, Kamalak Z, Ak D, Turhan NO. The impact of birth weight and maternal history on acne, hirsutism, and menstrua disorder symptoms in Turkish adolescent girls. Acta Obstet Gynecol Scand. 2012:41(3):473-8.

41. Buekens P, Delvoye P, Wollast E, Robyn C. Epidemiology of pregnancies with unknown last menstrual period. J Epidemiol Community Health. 1984;38(1):79-80.

42. Wang ET, Cirillo PM, Kao CN, Cohn BA, Cedars MI. Birth weight and childhood growth in daughters of women with irregular menstrual cycles. Gynecol Endocrinol. 2013;29(6):615-8.

43. Jaques AM, Amor DJ, Baker HWG, Healy DL, Ukoumunne OC, Breheny S, Garrett C, Halliday JL. Adverse obstetric and perinatal outcomes in subfertile women conceiving without assisted reproductive technologies. Fertil Steril. 2010;94(7):2674-9.

44. Woods KA, Camacho-Hübner C, Savage MO, Clark AJ. Intrauterine growth retardation and postnatal growth failure associated with deletion of the insulin-like growth factor I gene. N Engl J Med. 1996:335(18):1363-7.

45. Gluckman PD. Clinical review 68: the endocrine regulation of fetal growth in late gestation: the role of insulin-like growth factors. J Clin Endocrinol Metab. 1995:80(4):1047-50

46. Delmis J, Drazancic A, Ivanisevic M, Suchanek E. Glucose, insulin, HGH and IGF-I levels in maternal serum, amniotic fluid and umbilical venous serum: a comparison between late normal pregnancy and pregnancies complicated with diabetes and fetal growth retardation. J Perinat Med. 1992;20(1):47-56.

47. Giudice LC, de Zegher F, Gargosky SE, Dsupin BA, de las Fuentes L, Crystal RA, Hintz RL, Rosenfeld RG. Insulin-like growth factors and their binding proteins in the term and preterm human fetus and neonate with normal and extremes of intrauterine growth. J Clin Endocrinol Metab. 1995:80(5):1548-55.

48. Juul A, Bang P, Hertel NT, Main K, Dalgaard P, Jørgensen K, Müller J, Hall K, Skakkebaek NE. Serum insulin-like growth factor-l in 1030 healthy children, adolescents, and adults: relation to age, sex, stage of puberty, testicular size, and body mass index. J Clin Endocrinol Metab. 1994;78(3):744-52.

49. Xu B, Järvelin MR, Xu X, Wang Z, Qin H, Rimpelä A. Maternal menstrual history and small-for-gestational-age births in a population-based Chinese birth cohort. Early Hum Dev. 1997;49(3):183-92.

50. Nagata C, Wada K, Tsuji M, Hayashi M, Takeda N, Yasuda K. Association of hair dye use with circulating levels of sex hormones in premenopausal Japanese women. Eur J Pub Health. 2015;25(5):895-9.

51. Shin D, Song WO. Prepregnancy body mass index is an independent risk factor for gestational hypertension, gestational diabetes, preterm labor, and small- and large-for-gestational-age infants. J Matern Fetal Neonatal Med. 2015;28(14):1679-86.

52. El Rafei R, Abbas HA, Charafeddine L, Nakad P, Al Bizri A, Hamod D, Yunis KA. Association of pre-Pregnancy Body Mass Index and Gestational Weight Gain with preterm births and fetal size: an observational study from Lebanon. Paediatr Perinat Epidemiol. 2016:30(1):38-45.

53. Zhang B, Yang S, Yang R, Wang J, Liang S, Hu R, Xian H, Hu K, Zhang $Y$, Weaver $N L$, et al. Maternal Prepregnancy body mass index and small for gestational age births in Chinese women. Paediatr Perinat Epidemiol. 2016:30(6):550-4

54. Han YS, Ha EH, Park HS, Kim YJ, Lee SS. Relationships between pregnancy outcomes, biochemical markers and pre-pregnancy body mass index. Int Obes (Lond). 2011;35(4):570-7. 